\title{
Chronic kidney disease among adult participants of the ELSA-Brasil cohort: association with race and socioeconomic position
}

\author{
Sandhi M Barreto, ${ }^{1}$ Roberto M Ladeira, ${ }^{1,2}$ Bruce B Duncan, ${ }^{3}$ Maria Ines Schmidt, ${ }^{3}$ \\ Antonio A Lopes, ${ }^{4}$ Isabela M Benseñor, ${ }^{5}$ Dora Chor, ${ }^{6}$ Rosane H Griep, ${ }^{7}$ \\ Pedro G Vidigal, ${ }^{1}$ Antonio L Ribeiro, ${ }^{1}$ Paulo A Lotufo, ${ }^{5}$ José Geraldo Mill ${ }^{8}$
}

${ }^{1}$ Medical School \& Hospital das Clínicas, Universidade Federal de Minas Gerais, Belo Horizonte, Minas Gerais, Brazil

${ }^{2}$ Department of Health,

Belo Horizonte, Brazil

${ }^{3}$ Medical School, Universidade Federal do Rio Grande do Sul, Porto Alegre, Rio Grande do Sul, Brazil

${ }^{4}$ Department of Internal Medicine, Universidade Federal da Bahia, Salvador, Brazil ${ }^{5}$ Center for Clinical and Epidemiologic Research, Universidade de São Paulo, São Paulo, Brazil

${ }^{6}$ National School of Public Health, Fundação Oswaldo Cruz, Rio de Janeiro, Brazil ${ }^{7}$ Laboratory of Health and Environment Education, Fundação Oswaldo Cruz, Brazi ${ }^{8}$ Department of Physiological Sciences, Universidade Federal do Espírito Santo, Brazil

\section{Correspondence to} Professor Sandhi M Barreto, Faculdade de Medicina, Universidade Federal de Minas Gerais, Av. Alfredo Balena 190, Belo Horizonte CEP 30320050 Brazil:

sbarreto@medicina.ufmg.br

Received 26 March 2015 Revised 31 August 2015 Accepted 4 October 2015 Published Online First 28 October 2015

\begin{abstract}
Background There is increased interest in understanding why chronic kidney disease (CKD) rates vary across races and socioeconomic groups. We investigated the distribution of estimated glomerular filtration rate (eGFR), urinary albumin-creatinine ratio (ACR) and CKD according to these factors in Brazilian adults.
\end{abstract}

Methods Using baseline data (2008-2010) of 14636 public sector employees (35-74 years) enrolled in the Brazilian Longitudinal Study of Adult Health (ELSA)-Brasil multicentre cohort, we estimated the prevalence of CKD by sex, age, race and socioeconomic factors. CKD was defined as $A C R \geq 30 \mathrm{mg} / \mathrm{g}$ and/or eGFR $<60 \mathrm{~mL} / \mathrm{min} /$ $1.73 \mathrm{~m}^{2}$. GFR was estimated by CKD epidemiology collaboration without correction for race. We used logistic regression to estimate the association of race and socioeconomic position (education, income, social class and occupational nature) with CKD after adjusting for sex, age and several health-related factors.

Results The prevalence of high ACR or low eGFR, in isolation and combined, increased with age, and was higher in individuals with lower socioeconomic position and among black individuals and indigenous individuals. The overall prevalence of CKD was $8.9 \%$. After full adjustments, it was similar in men and women $(\mathrm{OR}=0.90 ; 95 \% \mathrm{Cl} 0.79$ to 1.02$)$ and increased with age $(\mathrm{OR}=1.07 ; 95 \% \mathrm{Cl} 1.06$ to 1.08$)$. Compared to white individuals, black individuals (OR=1.23; $95 \% \mathrm{Cl} 1.03$ to 1.47), 'pardos' (OR=1.16; $95 \% \mathrm{Cl} 1.00$ to 1.35) and Indigenous (OR=1.72; $95 \% \mathrm{Cl} 1.07$ to 2.76) people had higher odds for CKD. Having high school (OR=1.15; 95\% $\mathrm{Cl} 1.00$ to 1.34$)$ or elementary education $(O R=1.23$; $95 \% \mathrm{Cl} 1.03$ to 1.47$)$ increased the odds for CKD compared to those having a university degree.

Conclusions There were marked discrepancies in the increases in reduced eGFR and high ACR with age and race. The higher prevalences of CKD in individuals with lower educational status and in non-whites were not explained by differences in health-related factors.

\section{INTRODUCTION}

Chronic kidney disease (CKD) is one of the major public health problems of the 21 st century due to its high morbidity and associated mortality, elevated social and individual costs and increasing prevalence in most countries. ${ }^{1-5}$ It is a complex and progressive disease defined by persistent kidney damage, generally marked by urinary albumin-creatinine ratio
(ACR) equal or superior to $30 \mathrm{mg} / \mathrm{g}$, or a glomerular filtration rate (GFR) lower than $60 \mathrm{~mL} / \mathrm{min} /$ $1.73 \mathrm{~m}^{2}$. $^{6}$

CKD affects $10-16 \%$ of the adults living in Asia, Europe, Australia and the USA, ${ }^{7-10}$ but data on the incidence and prevalence of $\mathrm{CKD}$, considering its full spectrum, in the general population of Latin America, including Brazil, are very sparse. ${ }^{11}$ Most of the available data on the incidence and prevalence of CKD refer to estimates of people under renal replacement therapy (RRT), that is, maintenance dialysis or kidney transplants, and these figures show steady increases in recent years. ${ }^{12-14}$ According to a review study, 1.9 million patients are undergoing RRT worldwide, with an annual initiation rate at 73 per million population (pmp). ${ }^{15}$ Existing data indicate that the prevalence of patients under RRT in Latin America increased from 119 patients pmp in 1991 to $568 \mathrm{pmp}$ in 2008 , with a wide variation between countries. ${ }^{16}$

In Brazil, CKD is estimated to cause 4500-6000 deaths/year. ${ }^{17}$ Between 2000 and 2012, the number of patients with CKD receiving publicly financed maintenance dialysis increased by $3.6 \%$ per year, reaching a total number of 104433 in $2012 .{ }^{18}$ In $2011,31.2 \%$ of the patients under RRT were on the waiting list for renal transplant. ${ }^{19}$ However, there is no information regarding the prevalence of early stages of CKD in Brazilian adults.

Owing to the difficulty in direct measurement, the GFR is estimated by equations that take into consideration the serum creatinine, sex, age and a correction factor for black individuals because the concentration of serum creatinine is affected by muscle mass, which is generally greater in African-Americans. ${ }^{20}$ The most widely used equations estimated glomerular filtration rate (eGFR) are the modified diet in renal disease (MDRD) and the CKD epidemiology collaboration (CKD-EPI). ${ }^{21} 22$ However, there is evidence that the CKD-EPI equation is better for estimating GFR and for predicting prognosis, ${ }^{23} 24$ though the CKD-EPI proposing study developed in the USA included a limited number of elders and people of racial and ethnic minorities. ${ }^{22}$

In Brazil, two studies validated the CKD-EPI equation. One used the plasma clearance of Iohexol $^{25}$ as a gold standard and the other 51Cr-EDTA. ${ }^{26}$ The first study showed that CKD-EPI was better than MDRD at detecting a 
reduction in GFR, and that applying the correction term for race did not contribute to more accurate results. The second study found that CKD-EPI with race correction overestimated GFR in participants with GFR $\leq 60 \mathrm{~mL} / \mathrm{min} / 1.73 \mathrm{~m}^{2}$ and underestimate it in those with GFR over this value. ${ }^{26}$

Studies developed in several countries reported results about socioeconomic and racial/ethnic disparities in the prevalence, incidence and treatment of CKD. The data from US studies indicate that black and Hispanic individuals present worse indicators related to CKD than their white counterparts. ${ }^{27} 28$ A survey in England found that high albuminuria, but not low eGFR, remained associated with low socioeconomic indicators, after adjustment for ethnicity, lifestyle and clinical variables (obesity, diabetes, hypertension and smoking). ${ }^{29}$ Greater prevalence of obesity and uncontrolled hypertension and diabetes among non-white individuals are the most common reasons appointed for racial differences in ACR. ${ }^{30-33}$ The CARDIA study found faster rates of decline in the estimated GFR among young black individuals than among their white counterparts. ${ }^{30}$

Social and health inequities remain important problems in Brazil, despite the improvements in access to healthcare and quality of care observed in recent years. ${ }^{34}$ Of note, the prevalence of diabetes and hypertension is generally higher among non-white and low socioeconomic groups in the country. ${ }^{35-37}$ These conditions may lead to the social inequality in CKD occurrence and progression, as diabetes and hypertension ${ }^{38} 39$ are common underlying causal factors of CKD. However, very little is known regarding social and racial/skin colour differences in CKD prevalence based on GFR and/or albuminuria in Brazil. The present study describes the prevalence of CKD in adult participants of the Brazilian Longitudinal Study of Adult Health (ELSA)-Brasil cohort by means of the CKD-EPI equation and ACR level by sex, age and race/skin colour. It also estimates the association of education and race/skin colour with CKD prevalence after considering the effect of known health-related risk factors for CKD.

\section{METHODS}

\section{Study participants}

The Brazilian Longitudinal Study of Adult Health (ELSA-Brasil) is a multicentre prospective cohort study designed primarily to identify risk factors and the natural history of diabetes and cardiovascular disease (CVD). The cohort comprises 15105 active or retired employees, 35-74 years of age at baseline (20082010), from universities or research institutions located in six Brazilian capitals (Belo Horizonte, Porto Alegre, Rio de Janeiro, Salvador, Sao Paulo, Vitoria). ELSA-Brasil includes volunteers (76\% of the final sample) and actively recruited participants (24\%), the latter being recruited from listings of civil servants. Efforts were made to recruit similar proportions of men and women, as well as predefined proportions of age groups and occupational categories. Exclusion criteria were current or recent ( $<4$ months prior to the first interview) pregnancy, intention to quit working at the institution in the near future, severe cognitive or communication impairment, and, if retired, residence outside of a study centre's corresponding metropolitan area. The details of the study methodology, including design and eligibility criteria and the cohort's profile, have been previously described. ${ }^{40} 41$

The strategy to recruit civil servants was motivated to ensure a minimal dropout rate during follow-up. Since an appreciable proportion of manual and semi-skilled workers are hired as regular employees of universities and research institutions in
Brazil, this permits a wide gradient of socioeconomic position across the sample.

The ethics committee of each institution approved the research protocol, and volunteers gave written consent to participate.

For the current cross-sectional analyses, we excluded participants if they were missing information for serum creatinine $(n=8)$ or ACR $(n=461)$. Our final analytic sample comprised 14636 individuals (96.9\% of the cohort).

\section{Data collection}

\section{Outcome assessment}

ACR was calculated from the $12 \mathrm{~h}$ urine samples obtained from urine albumin and creatinine concentrations ${ }^{42}{ }^{43}$ The kinetic Jaffe method (Advia 1200 Siemens, USA) was used to measure urine creatinine, and the immunochemical assay (BN II Nephelometer Siemens Dade Behring, USA) to measure urine albumin.

A $12 \mathrm{~h}$ fasting blood sample was drawn by venipuncture soon after the patient arrived at the baseline clinic visit. ${ }^{42}{ }^{43}$ Baseline creatinine was measured in serum specimens by the kinetic Jaffé method (Advia 1200 Siemens, USA), after applying a conversion factor derived from calibration samples traceable to isotopedilution mass ${ }^{23}$ spectrometry.

eGFR using the CKD-EPI equation ${ }^{22}$ was calculated as follows:

$$
\begin{aligned}
\text { eGFRcreatinine }= & 141 \times \min (\mathrm{SCr} / \mathrm{k}, 1) \mathrm{a} \times \max (\mathrm{SCr} / \mathrm{k}, 1) \\
& -1.209 \times 0.993 \mathrm{Age} \times 1.018 \text { [if female] } \\
& \times 1.159 \text { [if black] }
\end{aligned}
$$

Where SCr is serum creatinine $(\mathrm{mg} / \mathrm{dL}), \mathrm{k}$ is 0.7 if female and 0.9 if male and $\mathrm{a}$ is -0.329 if female and -0.411 if male, and min indicates the minimum of $\mathrm{SCr} / \mathrm{k}$ or 1 , and max indicates the maximum of $\mathrm{SCr} / \mathrm{k}$ or 1 .

On the basis of the results of the two Brazilian validation studies of the CKD-EPI equation, ${ }^{25}{ }^{26}$ we decided to apply the equation with the correction factor for race. Thus, the eGFR shown is without correction for race. Individuals with eGFR $<60 \mathrm{~mL} / \mathrm{min} / 1.73 \mathrm{~m}^{2}$ (yes/no) and/or ACR $\geq 30 \mathrm{mg} / \mathrm{g}$ (yes/no) were classified as having CKD (yes/no).

\section{Exposure assessment}

The main predictor variables were sex, age in years (continuous), self-declared skin colour/race (white, black, 'pardo', indigenous and Asian descent), formal educational level achieved (elementary, high school or university), social class of the current occupation (high, middle, low) and occupational nature of the present job (manual, not manual but routine work, not manual and not routine work). 'Pardo' in our sample reflects mainly the admixture of white individuals and black individuals.

The following health covariates were included as adjusting factors in the analysis: hypertension, diabetes, CVD, body mass index, smoking status and total/HDL (high-density lipoprotein) cholesterol. Adjustments were made by these covariates because they are associated with both CKD and the socioeconomic factors assessed as the main predictor variables. ${ }^{44} 45$

Hypertension (no/yes) was defined as systolic blood pressure $=140 \mathrm{~mm} \mathrm{Hg}$ or diastolic blood pressure $=90 \mathrm{~mm} \mathrm{Hg}$ or verified treatment with antihypertensive medication. Diabetes status (no/yes) was classified using blood glucose and glycated haemoglobin (A1c) measurements and self-reported information. A participant was considered to have previously diagnosed 
diabetes when answering 'yes' to either "Have you been previously told by a physician that you had diabetes (sugar in the blood)?" or "Have you used medication for diabetes in the past 2 weeks?" The remaining ones were evaluated for undiagnosed diabetes based on their laboratory values and then classified as having diabetes if they reached the threshold for fasting plasma glucose $(=126 \mathrm{mg} / \mathrm{dL}), 2 \mathrm{~h}$ postload plasma glucose $(=200 \mathrm{mg} /$ $\mathrm{dL}$ ) or $\% \mathrm{~A} 1 \mathrm{c}(\geq 6.5 \%)$. Presence of CVD (no/yes) was defined on the basis of the report of coronary revascularisation, or of a medical diagnosis of myocardial infarct and/or) and/or stroke and/or heart failure.

Obesity (no/yes) was defined by body mass index (BMI) $>30 \mathrm{~kg} / \mathrm{m}^{2}$. Current cigarette smoking (no/yes) was determined by self-report during the interview. Total and HDL-cholesterol were determined by the enzymatic colorimetric method. The strategies for the collection, processing, transportation and quality control of blood and urine tests in the ELSA-Brasil cohort are described in detail elsewhere. ${ }^{42} 43$

\section{Statistical analysis}

First, we present the sociodemographic and health characteristics of participants of the ELSA Brasil cohort. We show the relative (\%) contribution of eGFR and ACR cut-off levels to define the presence of CKD by sex and according to skin colour. Then we show the distribution of participants according to combined KDIGO6 classes based on eGFR and ACR levels.

Multivariable logistic regression analysis was used to investigate the association of each socioeconomic indicator and skin colour with the presence of $\mathrm{CKD}$, before and after adjusting for age, sex and CKD common risk factors (smoking, obesity, diabetes, hypertension and total/HDL cholesterol). The magnitude of the associations was estimated by the OR and $95 \% \mathrm{CI}$. We retained in the full adjusted model only the variables that remained statistically associated with CKD at a level 5\% $(\mathrm{p}<0.05)$. The analysis was run using STATA, V.12.0.

\section{RESULTS}

The mean age of 14636 participants in this study was 52.2 (SD: 9.1) years (median $=51.0$ years). There was a slight predominance of female participants (54.1\%); 52.4\% self-declared themselves as white, $28.1 \%$ as 'pardo', $16.0 \%$ as black, $2.5 \%$ as being of Asian descent and $1.1 \%$ as indigenous. Over half of the individuals had a university degree. Most participants were middle class and had non-manual, non-routine jobs. Prevalence of hypertension and diabetes was $35.9 \%$ and $19.8 \%$, respectively. Most participants with hypertension (28.9\%) reported a previous diagnosis of this condition, and less than half $(8.8 \%)$ of those with diabetes were aware of their status. The prevalence of CVD was 4.9\%, 13\% smoked and 22.9\% had a BMI that exceeded $30 \mathrm{~kg} / \mathrm{m}^{2}$.

According to the $2012 \mathrm{KDIGO}$ criteria (figure 1), $38.3 \%$ of the participants had normal/high eGFR and normal to mildly increased ACR, whereas $52.7 \%$ of the participants had mildly decreased (G2) excretory renal function (eGFR: 60-89 mL/min/ $\left.1.73 \mathrm{~m}^{2}\right)$ with normal to mildly increased ACR $(<30 \mathrm{mg} / \mathrm{g})$. About $4.8 \%$ of the participants had a substantially reduced eGFR ( $\left.<60 \mathrm{~mL} / \mathrm{min} / 1.73 \mathrm{~m}^{2}\right)$, and $0.6 \%$ showed clinically relevant albuminuria (ACR $>300 \mathrm{mg} / \mathrm{g}$ ). Almost $4.0 \%$ of the participants presented with increased albuminuria with eGFR above $60 \mathrm{~mL} / \mathrm{min} / 1.73 \mathrm{~m}^{2}$.

As shown in table 1, almost $9 \%$ of the participants had CKD, that is, they had a decrease in eGFR and/or an increase in albuminuria, with the overall prevalence of CKD being greater among men (10.1\%) than among women (7.9\%). Table 1 also shows that in comparison with participants without CKD, the prevalences of CKD, and of the percentage with high ACR or low eGFR, in isolation and combined, increased with age, were higher in less educated, poorer individuals from a low social class and who had manual or non-manual routine jobs, as CKD was also more frequent among those who smoked or presented with obesity, hypertension, diabetes or CVD at baseline. Mean total/HDL cholesterol ratio was also higher among those with CKD, high ACR and low eGFR than among those without CKD.

Table 2 shows the prevalence of CKD based on the eGFR and ACR by age group and according to sex. The increase in the prevalence of CKD with age was greatest among men in all age groups. In men, CKD prevalence increases from 3.8\% among $35-44$-year-olds to $31.6 \%$ among $70-74$-year-olds. The increase is less steep among women, from $3.5 \%$ among the youngest group to $21.4 \%$ among the oldest one. As age increases, the contribution of eGFR to CKD increases. A marked disparity

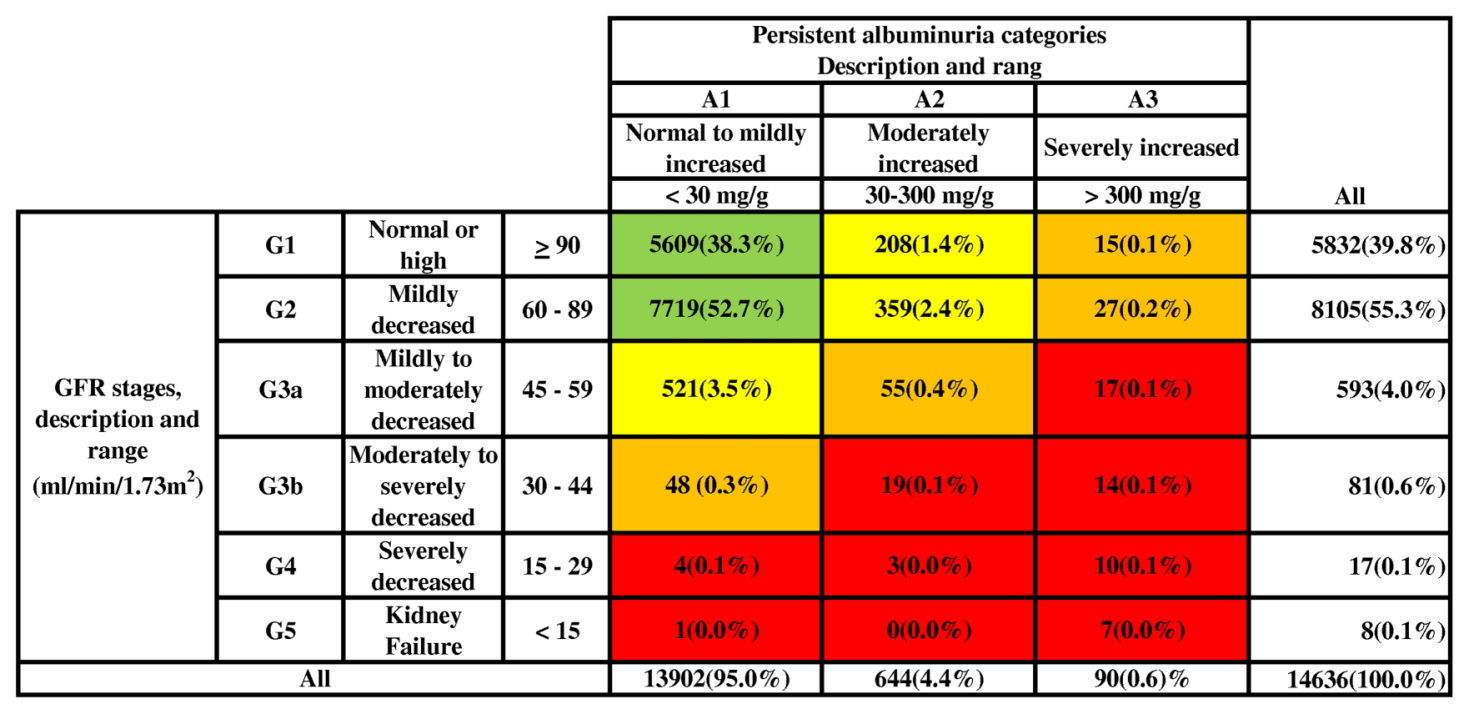

Figure 1 Percentage of ELSA participants by eGFR (CKD-EPI without correction for race) and albuminuria category-KDIGO, 2012 ${ }^{6}$ (N=14 636). CKD-EPI, chronic kidney disease epidemiology collaboration; eGFR: estimated glomerular filtration rate; ELSA, The Brazilian Longitudinal Study of Adult Health. 
Table 1 Sociodemographic and health characteristics of participants of the ELSA-Brasil cohort according to the presence of CKD and criteria for CKD: 2008-2010 ( $\mathrm{N}=14$ 636)

\begin{tabular}{|c|c|c|c|c|c|}
\hline \multirow[b]{2}{*}{ Variables } & \multicolumn{2}{|l|}{ CKD } & \multicolumn{3}{|l|}{ Criteria for CKD } \\
\hline & $\begin{array}{l}\text { No } \\
\text { N (\%) }\end{array}$ & $\begin{array}{l}\text { Yes } \\
\mathrm{N}(\%)\end{array}$ & $\begin{array}{l}A C R \geq 30 \text { alone } \\
N(\%)\end{array}$ & $\begin{array}{l}\text { eGFR<60 alone } \\
\mathrm{N}(\%)\end{array}$ & $\begin{array}{l}\text { Both } \\
\mathrm{N}(\%)\end{array}$ \\
\hline All & $13328(91.1)$ & $1308(8.9)$ & $609(4.1)$ & $574(3.9)$ & $125(0.9)$ \\
\hline \multicolumn{6}{|l|}{ Gender } \\
\hline Male & 6038 (89.9) & $680(10.1)$ & $316(4.7)$ & $274(4.1)$ & $90(1.3)$ \\
\hline Female & $7290(92.1)$ & $628(7.9)$ & $293(3.7)$ & $300(3.8)$ & $35(0.4)$ \\
\hline \multicolumn{6}{|l|}{ Age group (years) } \\
\hline $35-44$ & 3090 (96.4) & $116(3.6)$ & $93(2.9)$ & $20(0.6)$ & $3(0.1)$ \\
\hline $45-54$ & $5406(94.3)$ & $329(5.7)$ & 225 (3.9) & $80(1.4)$ & $24(0.4)$ \\
\hline $55-64$ & 3680 (88.9) & 459 (11.1) & $204(4.9)$ & $218(5.3)$ & $37(0.9)$ \\
\hline 65-74 & $1152(74.0)$ & $404(26.0)$ & 87 (5.6) & $256(16.5)$ & $61(3.9)$ \\
\hline \multicolumn{6}{|l|}{ Race/skin colour } \\
\hline White & $6974(92.1)$ & $601(7.9)$ & $245(3.2)$ & $304(4.0)$ & $52(0.7)$ \\
\hline Black & 2061 (88.9) & $258(11.1)$ & $128(5.5)$ & $103(4.4)$ & $27(1.2)$ \\
\hline 'Pardo' & $3683(90.8)$ & $374(9.2)$ & $197(4.8)$ & $138(3.4)$ & $39(1.0)$ \\
\hline Asian descent & 331 (91.9) & $29(8.1)$ & $14(3.9)$ & $11(3.1)$ & $4(1.1)$ \\
\hline Indigenous & $129(84.3)$ & $24(15.7)$ & $13(8.5)$ & $9(5.9)$ & $2(1.3)$ \\
\hline \multicolumn{6}{|l|}{ Educational level } \\
\hline University & 7136 (92.7) & $565(7.3)$ & $229(3.0)$ & $291(3.8)$ & $45(0.5)$ \\
\hline High school & 4614 (91.1) & $450(8.9)$ & $253(5.0)$ & $160(3.2)$ & $37(0.7)$ \\
\hline Elementary & $1578(84.3)$ & $293(15.7)$ & $127(6.8)$ & $123(6.6)$ & $43(2.3)$ \\
\hline \multicolumn{6}{|l|}{ Income (quintile) } \\
\hline 1—Highest & 2158 (89.9) & $242(10.1)$ & 74 (3.1) & $145(6.0)$ & $23(1.0)$ \\
\hline 2 & 3025 (92.1) & $260(7.9)$ & 117 (3.6) & $123(3.7)$ & $20(0.6)$ \\
\hline 3 & 2761 (91.5) & $258(8.5)$ & $122(4.0)$ & $107(3.5)$ & $29(1.0)$ \\
\hline 4 & $2694(91.7)$ & $243(8.3)$ & $128(4.4)$ & $101(3.4)$ & $14(0.5)$ \\
\hline 5-Lowest & 2630 (89.8) & $300(10.2)$ & $167(5.7)$ & $94(3.2)$ & $39(1.3)$ \\
\hline \multicolumn{6}{|l|}{ Social class } \\
\hline High & $4408(91.8)$ & $395(8.2)$ & $147(3.1)$ & $212(4.4)$ & $36(0.7)$ \\
\hline Middle & $5532(91.9)$ & $487(8.1)$ & $257(4.3)$ & $196(3.3)$ & $34(0.5)$ \\
\hline Low & $3174(88.7)$ & $404(11.3)$ & $194(5.4)$ & $160(4.5)$ & $50(1.4)$ \\
\hline \multicolumn{6}{|l|}{ Occupational nature } \\
\hline Non-manual/non-routine & $7030(92.2)$ & $598(7.8)$ & $246(3.2)$ & $304(4.0)$ & $48(0.6)$ \\
\hline Non-manual/routine & $3759(90.7)$ & $385(9.3)$ & $196(4.8)$ & $160(3.9)$ & $29(0.6)$ \\
\hline Manual & $2303(88.7)$ & $294(11.3)$ & $152(5.8)$ & $100(3.8)$ & $42(1.6)$ \\
\hline \multicolumn{6}{|l|}{ Current smoking } \\
\hline No & $11600(91.2)$ & $1126(8.8)$ & $492(3.8)$ & $524(4.1)$ & $110(0.9)$ \\
\hline Yes & $1727(90.5)$ & $182(9.5)$ & $117(6.1)$ & $50(2.6)$ & $15(0.8)$ \\
\hline \multicolumn{6}{|l|}{ Cardiovascular disease } \\
\hline No & $12749(91.7)$ & $1148(8.3)$ & $548(4.0)$ & $495(3.6)$ & $105(0.7)$ \\
\hline Yes & $560(78.5)$ & $153(21.5)$ & $57(8.0)$ & $76(10.7)$ & $20(2.8)$ \\
\hline \multicolumn{6}{|l|}{ Diabetes } \\
\hline No & $10981(93.5)$ & $764(6.5)$ & $343(2.9)$ & $380(3.2)$ & $41(0.4)$ \\
\hline Yes & $2346(81.2)$ & $544(18.8)$ & $266(9.2)$ & $194(6.7)$ & $84(2.9)$ \\
\hline \multicolumn{6}{|l|}{ Hypertension } \\
\hline No & $8918(95.2)$ & $453(4.8)$ & $237(2.5)$ & $200(2.1)$ & $16(0.2)$ \\
\hline Yes & $4400(83.8)$ & $852(16.2)$ & $372(7.1)$ & $372(7.1)$ & $108(2.0)$ \\
\hline \multicolumn{6}{|l|}{ Obesity } \\
\hline $\mathrm{BMI}<30 \mathrm{~kg} / \mathrm{m}^{2}$ & $10395(92.1)$ & $891(7.9)$ & 393 (3.5) & 412 (3.7) & $86(0.7)$ \\
\hline $\mathrm{BMI}>30 \mathrm{~kg} / \mathrm{m}^{2}$ & $2928(87.5)$ & $417(12.5)$ & $216(6.5)$ & $162(4.9)$ & $39(1.1)$ \\
\hline \multicolumn{6}{|l|}{ Total/HDL cholesterol ratio } \\
\hline Mean (SD) & $3.94(1.02)$ & $4.17(1.36)$ & 4.24 (1.62) & $4.05(1.07)$ & $4.37(1.06)$ \\
\hline
\end{tabular}

ACR, albumin-creatinine ratio (mg/g); BMI, body mass index; CKD, chronic kidney disease; CKD-EPI, chronic kidney disease epidemiology collaboration; ELSA, The Brazilian Longitudinal Study of Adult Health; eGFR, glomerular filtration rate estimated by CKD-EPI without correction for race/skin colour black $(\mathrm{mL} / \mathrm{min} / 1.73 \mathrm{~m})^{2}$; HDL, high-density lipoprotein.

was seen between the increases in eGFR and ACR by age, the latter, in isolated form, detecting, in absolute terms, $50 \%$ more CKD in the 65-74-year-olds compared to the 35-44-year-olds.
On the other hand, isolated eGFR detected, in absolute terms, a 20 -fold increase in CKD prevalence. The prevalence of isolated high ACR increased with age among men, but there was no 
Table 2 Distribution of participants according to eGFR (mL/min/1.73 $\mathrm{m}^{2}$ ) estimated by CKD-EPI equation and ACR (mg/g) cut-offs used to define the presence of CKD by sex and age group; ELSA Brasil, 2008-2010 ( $N=14$ 636)

\begin{tabular}{|c|c|c|c|c|c|}
\hline \multirow[b]{2}{*}{ Male $(n=6718)$} & \multirow[b]{2}{*}{ All } & \multicolumn{4}{|c|}{ Age group (\%) } \\
\hline & & $35-44$ & $45-54$ & $55-64$ & $65-74$ \\
\hline \multicolumn{6}{|l|}{ Without CKD } \\
\hline eGFR $\geq 60$ and $A C R<30$ & 89.9 & 96.2 & 93.5 & 88.0 & 69.4 \\
\hline With CKD (overall) & 10.1 & 3.8 & 6.5 & 12.0 & 31.6 \\
\hline $\mathrm{eGFR} \geq 60$ and $A C R \geq 30$ & 4.7 & 2.9 & 4.4 & 5.7 & 7.1 \\
\hline eGFR $<60$ and $A C R<30$ & 4.1 & 0.8 & 1.5 & 5.1 & 16.9 \\
\hline \multirow[t]{2}{*}{ eGFR $<60$ and $A C R \geq 30$} & 1.3 & 0.1 & 0.6 & 1.2 & 6.6 \\
\hline & & \multicolumn{4}{|c|}{ Age group (\%) } \\
\hline Female $(n=7918)$ & All & $35-44$ & $45-54$ & $55-64$ & 65-74 \\
\hline \multicolumn{6}{|l|}{ Without CKD } \\
\hline $\mathrm{eGFR} \geq 60$ and $A C R<30$ & 92.1 & 96.5 & 94.9 & 89.6 & 78.6 \\
\hline With CKD (overall) & 7.9 & 3.5 & 5.1 & 10.4 & 21.4 \\
\hline eGFR $\geq 60$ and $A C R \geq 30$ & 3.7 & 2.9 & 3.5 & 4.4 & 4.1 \\
\hline eGFR $<60$ and $A C R<30$ & 3.8 & 0.5 & 1,3 & 5,4 & 16.0 \\
\hline eGFR $<60$ and $A C R \geq 30$ & 0.4 & 0.1 & 0.3 & 0.6 & 1.3 \\
\hline
\end{tabular}

Bold indicates results that are statistically significant at $p<0.05$.

ACR, albumin-creatinine ratio (mg/g); CKD, chronic kidney disease; CKD-EPI, CKD epidemiology collaboration; eGFR, glomerular filtration rate ( $\mathrm{mL} / \mathrm{min} / 1.73$ m²) estimated by CKD-EPI without correction for race/skin colour black; ELSA, The Brazilian Longitudinal Study of Adult Health.

clear trend among women, and it was higher among older men than among women. In the age group $65-74$ years, the prevalence of $A C R \geq 30 \mathrm{mg} / \mathrm{g}$ in persons with $\mathrm{eGFR}<60 \mathrm{~mL} / \mathrm{min} /$ $1.73 \mathrm{~m}^{2}$ was approximately $70 \%$ higher in men than in women.

Figure 2A-C shows the prevalence of CKD among men and women according to skin colour and the criteria used to define the presence of CKD. Among men, the prevalence of high ACR is greatest among black individuals and of low eGFR among indigenous individuals. Among women, indigenous individuals presented the highest prevalence of high ACR and of low eGFR.

The results of the unadjusted regression analysis in table 3 show that the chances of having CKD are greater among men, increase with age and are higher among participants with lower socioeconomic position for all social markers used (educational status, Income per capita, social class and occupational nature). People who reported their race/skin colour as black, 'pardo' or indigenous also have a greater chance of CKD compared to white individuals. Smoking, obesity, diabetes, hypertension and CVD were all associated with higher chances of CKD. The presence of CKD rose with increasing total/HDL cholesterol ratio.

After adjusting for age and sex (table 3), the chances of CKD did not differ by sex, but remained greater among individuals with lower socioeconomic position (all indicators) or who declared themselves as black, 'pardo' or indigenous. All the other covariates also remained statistically associated with higher chances of CKD in the same direction as the crude analysis. However, after further adjustments for the health related factors included in table 3 , the associations with lower income quintile, social class and occupational nature all lost statistical significance. Having high school $(\mathrm{p}=0.05)$ or elementary education $(\mathrm{p}<0.01)$ and skin colour/race black, 'pardo' or indigenous remained independently associated with greater chances of CKD (table 3).

\section{DISCUSSION}

Using the 2012 KDIGO criteria, ${ }^{6}$ we found that nearly 1 in every 10 adults enrolled in the ELSA-Brasil cohort has CKD. The estimated prevalence of CKD in this Brazilian cohort is closer to the ones reported in some countries, ${ }^{79}$ but lower than that found in England. ${ }^{46}$ However, comparing the prevalence of CKD among studies is quite difficult because of differences in sociodemographic characteristics and in the equation used to estimate GFR. ${ }^{47}$ For instance, the ELSA-Brasil cohort does not include the oldest age group ( $\geq 75$ years), which has the highest prevalence of CKD, and over $50 \%$ of the cohort have a university degree, a condition associated with lower CKD prevalence, as seen in our study. Also, GFR estimated by CKD-EPI is lower than that estimated by the MDRD equation. ${ }^{21}$ In the Whitehall study, which is also a cohort of civil servants, the prevalence of low GFR based on the CKD-EPI equation was 7.8\% for men, higher than what we have found (4.6\% for men) but the mean age of the Whitehall cohort is 65.5 years, while that of the ELSA cohort is 52.2 years. ${ }^{48}$ As in most studies, we found that the prevalence was particularly high for early stages of $\mathrm{CKD}$, that is, the stages represented by a mild decrease in GFR or moderate increases in ACR. Owing to the high prevalence, these early stages of CKD in adults living in different regions of Brazil are likely to play an important role in the population attributable risk for fatal and non-fatal outcomes associated with CKD, particularly CVD. ${ }^{3} 49$

Our results indicate the greater contribution of ACR than of eGFR to CKD prevalence among younger individuals and of low eGFR among older participants. We also found that the contribution of ACR and eGFR to CKD differed by subgroups of gender and race/skin colour. In women, the role of ACR in defining CKD is lowest among white individuals and greatest among indigenous individuals. In men, the contribution of ACR to $\mathrm{CKD}$ prevalence was lowest among those of Asian descent and white individuals and highest among black individuals.

There has been some debate as to whether low eGFR and increased ACR in older people should be viewed as a disease or a natural result of the ageing process. ${ }^{21}$ It is important to note that, regardless of the cause of the alteration in kidney damage or function, for all age groups the risk of adverse outcomes (mortality and cardiovascular outcomes) increases with CKD progression. However, the magnitude of the excess risk associated with more advanced CKD stage varies by age groups 
Figure 2 (A-C)-Percentage of participants with reduced eGFR and/or elevated ACR by sex and according to race/skin colour. ELSA-Brasil, 2008-2010 ( $N=14$ 464). eGFR (given as $\mathrm{mL} / \mathrm{min} / 1.73 \mathrm{~m}^{2}$ ) estimated by CKD-EPI without correction for race/ skin colour black; ACR (given as mg/g). $A C R$, albumin-creatinin rate; CKD-EPI, chronic kidney disease epidemiology collaboration; eGFR: estimated glomerular filtration rate; ELSA, The Brazilian Longitudinal Study of Adult Health.

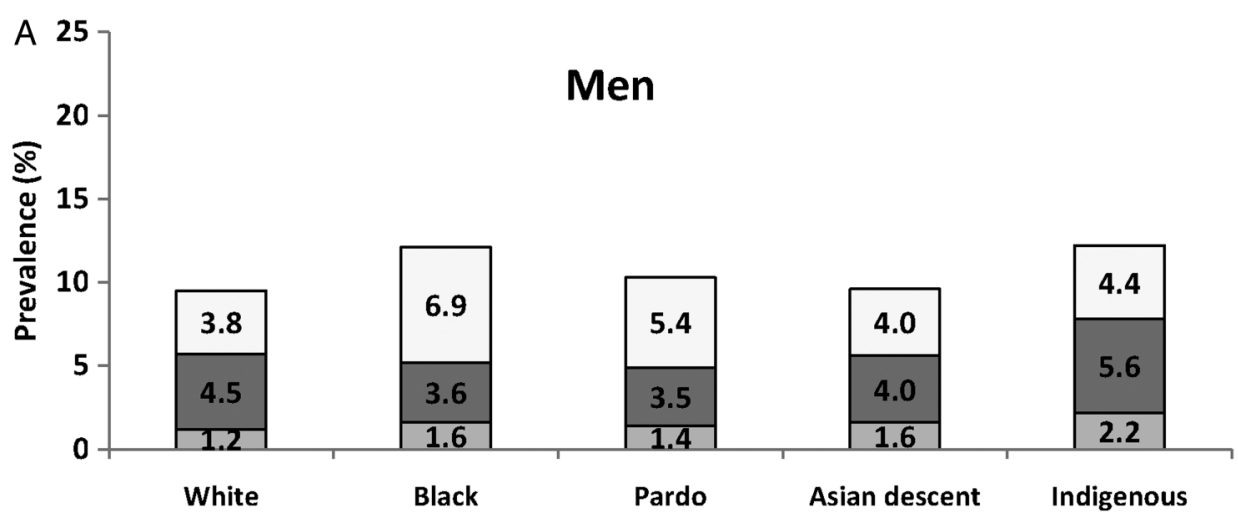

$\square$ eGFR $<60$ and ACR $>30 \square$ eGFR<60 and ACR $<30 \square$ eGFR $>60$ and ACR $>30$

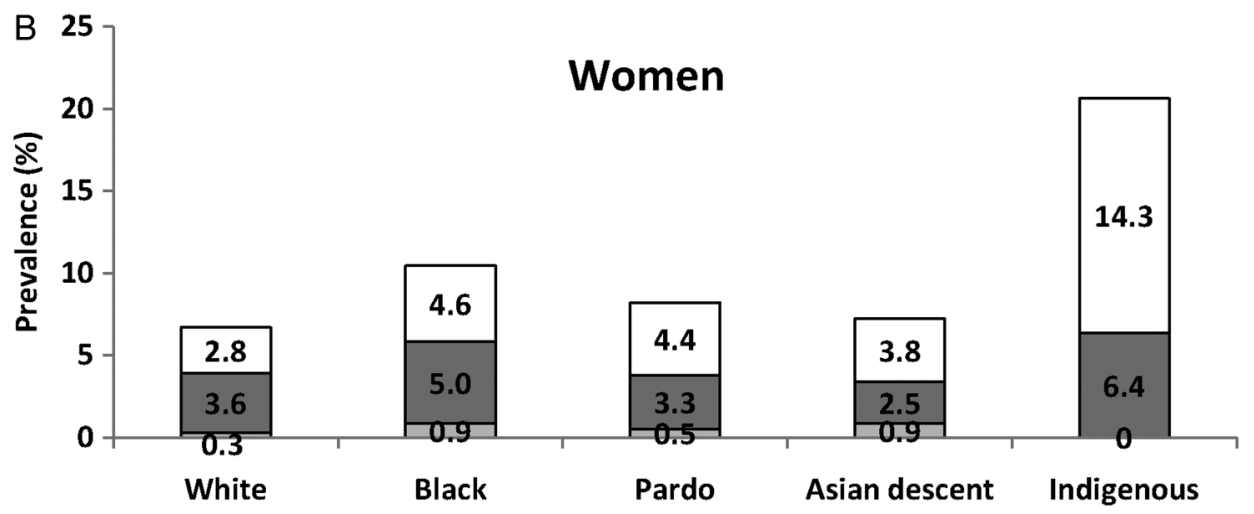

$\square$ eGFR<60 and ACR $>30 \square$ eGFR $<60$ and ACR $<30 \quad \square$ eGFR $>60$ and ACR $>30$

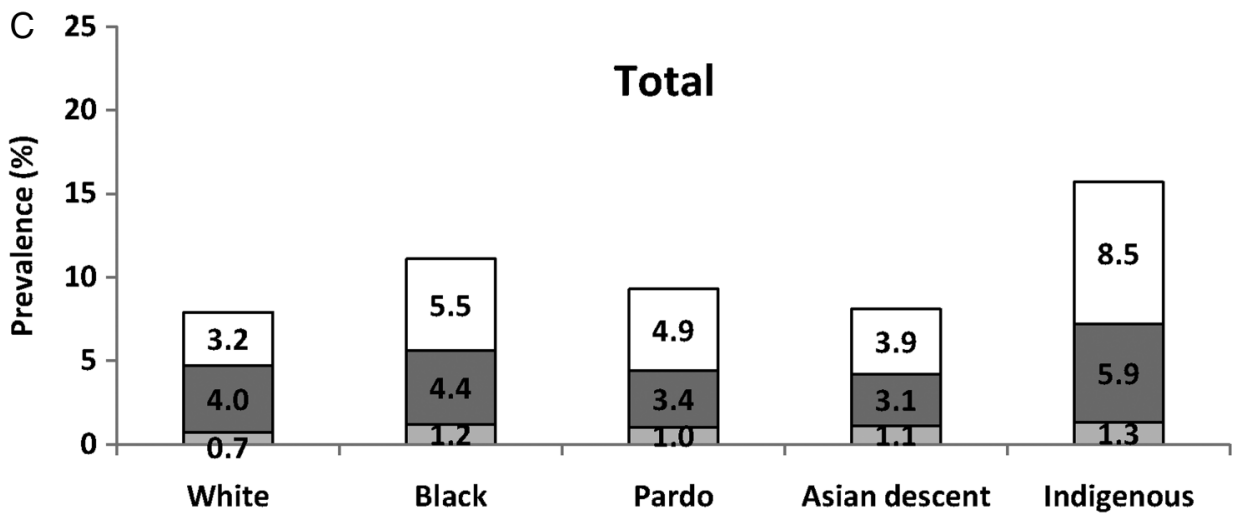

$\square \mathrm{eGFR}<60$ and $A C R>30 \quad \square \mathrm{eGFR}<60$ and $A C R<30 \quad \square \mathrm{eGFR}>60$ and $A C R>30$ depending on the measure of association that is used, that is, rate difference or rate ratio. When relative risk is used, the increase in the magnitude of the association between lower eGFR and all-cause mortality as well as end-stage renal disease (ESRD) progression in older groups is less pronounced. In contrast, the increase in the risk differences of all-cause mortality and ESRD progression between individuals with lower and higher eGFR is more pronounced for the older than for the younger groups.

We found that the prevalence of $A C R \geq 30 \mathrm{mg} / \mathrm{g}$ is higher for black individuals and indigenous individuals as compared to white individuals. Similar to what we have observed, the NHANES III survey in the USA found greater odds of albuminuria for black individuals compared with white individuals. ${ }^{38}$ Albuminuria is an important marker for the onset and progression of CKD, and for CVD. ${ }^{50}$ Since albuminuria is a direct manifestation of kidney injury, it may be viewed as a better indicator of outcomes related to CKD than GFR when it is estimated from serum creatinine. ${ }^{51}$ However, the combination of albuminuria with estimated GFR may improve the ability to predict ESRD onset and most likely the risk of fatal and nonfatal cardiovascular outcomes. ${ }^{52} 53$

The reasons for the higher prevalence of CKD in black, 'pardo' and indigenous individuals than in white individuals could not be fully explained by the sociodemographic factors and health risk factors in this study. Similar differences in the 
Table 3 Factors associated with the prevalence of CKD* in participants of the ELSA Brasil cohort in the univariate, age and gender adjusted and multivariate analysis, 2008-2010 ( $\mathrm{N}=14636)$

\begin{tabular}{|c|c|c|c|c|c|c|}
\hline \multirow[b]{2}{*}{ Variables } & \multicolumn{2}{|c|}{ Crude OR } & \multicolumn{2}{|c|}{ Adjusted age and sex } & \multicolumn{2}{|c|}{ Full adjustment } \\
\hline & OR & $95 \% \mathrm{Cl}$ & $\mathrm{OR}_{1}$ & $95 \% \mathrm{Cl}$ & $\mathrm{OR}_{2}$ & $95 \% \mathrm{Cl}$ \\
\hline \multicolumn{7}{|l|}{ Gender } \\
\hline Male & 1 & & 1 & & 1 & \\
\hline Female & 0.76 & 0.68 to 0.85 & 0.77 & 0.69 to 0.87 & 0.90 & 0.79 to 1.02 \\
\hline Age in years (mean/SD) & 1.09 & 1.08 to 1.10 & 1.09 & 1.08 to 1.10 & $1.07^{++}$ & 1.06 to 1.08 \\
\hline \multicolumn{7}{|l|}{ Race/skin colour } \\
\hline White & 1 & & 1 & & 1 & \\
\hline Black & 1.45 & 1.24 to 1.69 & 1.69 & 1.44 to 1.98 & $1.23^{+}$ & 1.03 to 1.47 \\
\hline 'Pardo' & 1.17 & 1.03 to 1.35 & 1.40 & 1.21 to 1.60 & $1.16^{+}$ & 1.00 to 1.35 \\
\hline Asian descent & 1.01 & 0.69 to 1.50 & 0.94 & 0.63 to 1.40 & 0.90 & 0.59 to 1.23 \\
\hline Indigenous & 2.16 & 1.38 to 3.36 & 2.09 & 1.32 to 3.31 & $1.72^{++}$ & 1.07 to 2.76 \\
\hline \multicolumn{7}{|l|}{ Education } \\
\hline University & 1 & & 1 & & 1 & \\
\hline High school & 1.23 & 1.08 to 1.40 & 1.51 & 1.32 to 1.73 & 1.15 & 1.00 to 1.34 \\
\hline Elementary & 2.34 & 2.01 to 2.73 & 1.74 & 1.49 to 2.03 & $1.23^{+}$ & 1.03 to 1.47 \\
\hline \multicolumn{7}{|l|}{ Income per capita (quintile) } \\
\hline 1-Highest & 1 & & 1 & & 1 & \\
\hline 2 & 0.76 & 0.63 to 0.92 & 1.04 & 0.86 to 1.26 & 0.95 & 0.77 to 1.16 \\
\hline 3 & 0.83 & 0.69 to 1.00 & 1.29 & 1.06 to 1.57 & 1.03 & 0.83 to 1.28 \\
\hline 4 & 0.80 & 0.66 to 0.96 & 1.32 & 1.08 to 1.60 & 0.90 & 0.70 to 1.14 \\
\hline 5-Lowest & 1.01 & 0.85 to 1.21 & 1.61 & 1.33 to 1.95 & 0.98 & 0.76 to 1.25 \\
\hline \multicolumn{7}{|l|}{ Social class } \\
\hline High & 1 & & 1 & & 1 & \\
\hline Middle & 0.98 & 0.85 to 1.12 & 1.48 & 1.28 to 1.72 & 1.03 & 0.83 to 1.27 \\
\hline Low & 1.42 & 1.22 to 1.64 & 1.57 & 1.35 to 1.83 & 0.89 & 0.67 to 1.17 \\
\hline \multicolumn{7}{|l|}{ Occupational nature } \\
\hline Non-manual non-routine & 1 & & 1 & & 1 & \\
\hline Non-manual routine & 1.20 & 1.05 to 1.17 & 1.39 & 1.21 to 1.60 & 0.99 & 0.81 to 1.22 \\
\hline Manual & 1.50 & 1.29 to 1.73 & 1.50 & 1.29 to 1.75 & 1.01 & 0.76 to 1.35 \\
\hline \multicolumn{7}{|l|}{ Smoking } \\
\hline No & 1 & & 1 & & 1 & \\
\hline Yes & 1.08 & 0.92 to 1.28 & 1.19 & 1.00 to 1.41 & $1.21^{+}$ & 1.01 to 1.44 \\
\hline \multicolumn{7}{|l|}{ CVD } \\
\hline No & 1 & & 1 & & 1 & \\
\hline Yes & 3.03 & 2.51 to 3.66 & 1.71 & 1.40 to 2.09 & $1.33^{+}$ & 1.08 to 1.64 \\
\hline \multicolumn{7}{|l|}{ Diabetes } \\
\hline No & 1 & & 1 & & 1 & \\
\hline Yes & 3.33 & 2.96 to 3.75 & 2.36 & 2.09 to 2.67 & $1.79^{++}$ & 1.57 to 2.04 \\
\hline \multicolumn{7}{|l|}{ Hypertension } \\
\hline No & 1 & & 1 & & 1 & \\
\hline Yes & 3.81 & 3.38 to 4.29 & 2.56 & 2.26 to 2.91 & $2.02^{++}$ & 1.77 to 2.31 \\
\hline \multicolumn{7}{|l|}{ Obesity } \\
\hline No & 1 & & & & & \\
\hline Yes & 1.66 & 1.46 to 1.88 & 1.67 & 1.47 to 1.90 & $1.17^{++}$ & 1.02 to 1.35 \\
\hline Total/HDL Chol & 1.20 & 1.14 to 1.26 & 1.23 & 1.16 to 1.30 & $1.14^{++}$ & 1.08 to 1.21 \\
\hline
\end{tabular}

${ }^{*}$ CKD: ACR $>30 \mathrm{mg} / \mathrm{g}$ and/or eGFR<60 $\mathrm{mL} / \mathrm{min} / 1.73 \mathrm{~m}^{2}$ estimated by the CKD-EPI equation without correction for race/skin colour.

$+: \mathrm{p}, 0.05 ;++\mathrm{p}<0.01$.

Bold indicates results that are statistically significant at $p<0.05$.

$\mathrm{OR}_{1}$ : $\mathrm{OR}$ adjusted for age and sex; $\mathrm{OR}_{2}$ : adjusted for all the variables that remained statistically significant (gender, age, race/skin colour, education, smoking, cardiovascular disease, diabetes, hypertension, obesity, total cholesterol/HDL ratio). Income, social class and occupational nature were not kept in the multivariable model.

ACR, albumin-creatinine ratio; CKD, chronic kidney disease; CVD, cardiovascular disease; CKD-EPI, CKD epidemiology collaboration; ELSA, The Brazilian Longitudinal Study of Adult Health; HDL, high-density lipoprotein; Total/HDL Chol, total/HDL cholesterol ratio.

prevalence and incidence of CKD by race have been reported by studies carried out elsewhere. ${ }^{38} 3954$ In ELSA-Brasil, the overall prevalence of hypertension and of uncontrolled and resistant hypertension was greatest among black and 'pardo' individuals. $^{5556}$ Similarly, the prevalence of obesity and diabetes was greatest among black and indigenous ELSA participants. ${ }^{57}$ For this reason, we believe that the differences in CKD prevalence by race in ELSA-Brasil are mostly explained by health inequalities that were not captured by the adjustments made in the multivariable analysis.

Results of a Brazilian validation study did not recommend applying the correction for race in the estimation of GFR using CKD-EPI. ${ }^{25}$ However, the small number of black individuals prevented the authors from performing a stratified 
analysis by race/skin colour. The validation study in South Brazil found that CKD-EPI with race correction underestimated GFR by $12 \mathrm{~mL} / \mathrm{min} / 1.73 \mathrm{~m}^{2}(\mathrm{SD}=16)$ in individuals with reduced GFR $\left(<60 \mathrm{~mL} / \mathrm{min} / 1.73 \mathrm{~m}^{2}\right)$ and overestimated GFR by $9 \mathrm{~mL} / \mathrm{min} / 1.73 \mathrm{~m}^{2}(\mathrm{SD}=22)$ in those with higher GFR. Results of this study also showed that, compared to MDRD, CKD-EPI performed worse only for black individuals when the race correction factor was applied. The authors then reanalysed the data for the set of 48 individuals of African origin without correction for race, and reported that the bias in GFR estimated by CKD-EPI was reduced in those with low GFR. ${ }^{26}$ Morevover, the use of the CKD-EPI race correction for black South Africans led to an overestimation of measured GFR by $12 \mathrm{~mL} / \mathrm{min} / 1.73 \mathrm{~m}^{2}$, indicating a different relationship between serum creatinine and GFR for Black South Africans than for North American and European Blacks. ${ }^{58}$ Brazilian black individuals come from a different region of the African continent than black individuals settled in the USA. ${ }^{59}{ }^{60}$ Thus, applying the race correction factor of the CKDEPi equation to black seems unsuited to Brazilian black individuals. However, we need to investigate in a larger sample of black Brazilians whether some degree of adjustment for race is necessary to improve GFR estimates, such as those made by Asian countries. ${ }^{61-63}$ The ELSA follow-up strategy might also help to answer this question as we will be able to trace creatinine changes with time as well as to monitor CKD-related morbidity and mortality. ${ }^{64}$

If our finding of greatest prevalence of CKD among black and 'pardo' individuals cannot be generalised to the Brazilian population, as is most likely, the similar distributions by race/skin colour of patients under RRT and the 2010 population census $^{17} 18$ indicate that black, 'pardo' and indigenous individuals may have less access to RRT than other skin colour groups. It is also possible that the finding of de Moura et al ${ }^{18}$ that the proportion of black and indigenous individuals among Brazilian RRT patients is similar to that expected by population census is caused by lower survival of black and indigenous RRT patients when compared to white ones. ${ }^{18}$ The Reasons for Geographic and Racial Differences in Stroke (REGARDS) study followed up over 2700 individuals with CKD stages 3 and 4 and found that black patients had higher mortality than white ones even after adjusting for important sociodemographic and clinical factors after 4-years follow-up. ${ }^{65}$

In the fully adjusted analysis, only education, among the four SE indicators considered, remained associated with higher chances of CKD in a graded fashion. After controlling for clinical and laboratorial risk factors for CKD, the magnitude of the ORs reduced and was of borderline significance for participants with "high school" as compared to those with university degree. These factors probably reflect a downward bias caused by overadjustment for potential mediators in the causal pathway between socioeconomic conditions and CKD. For instance, adverse socioeconomic status is an independent risk factor for CVDs, and CVD increases the risk of CKD. Thus, part of the association between socioeconomic status and CKD is lost when we include CVD as an adjusting factor in the association between socioeconomic indicators and CKD. ${ }^{66}$ The same reasoning would apply to other adjusting factors, such as hypertension and diabetes.

The strength of this study is the quality of its data collection and the size and diversity of the sample studied. The various means of ascertainment permit a full accounting of the prevalence of CKD, which has not been accomplished previously in a large survey of Brazilian adults. Even though the interpretation of association found in cross-sectional studies is often threatened by reverse causation, this is not the case for the association between race/skin colour and CKD.

Weaknesses were also identified in this study. As ELSA-Brasil was conducted in six of Brazil's state capitals, these results offer limited scope for generalisation to Brazil's overall adult population. Our sample, consisting of employees from university and research institute employees with stable employment and most with high educational achievement, is not representative of the Brazilian population. However, comparisons between the prevalence of important risk factors for CKD, such as hypertension and diabetes, indicate that they are close to the prevalence estimated from the probabilistic sample of a Brazilian telephone interview survey (VIGITEL) ${ }^{41}$ in the same age ranges. The small number of missing data (3.1\%) makes it unlikely that missing data had a relevant influence on our overall results.

Another concern is that persistence of reduced GFR and/or of high ACR is required to confirm CKD, and this might have led to non-differential misclassification of some individuals, biasing the associations towards the null. In this study, serum creatinine was measured in a single blood sample and ACR was tested in a single sample of $12 \mathrm{~h}$ urine collection. Our measure is thus more likely to express the true biological mean of the daily excretion of these two substances than one single morning sample. ${ }^{67}$ Fluctuations in creatinine have been shown to have a strong influence on CKD prevalence. ${ }^{68}$ Longitudinal data will help to confirm the findings of this study.

In conclusion, in this large cohort of Brazilians, we found that almost 1 in every 10 participants had CKD, and that CKD was especially prevalent among those with less education, as well as black or 'pardo' and indigenous individuals. The results suggest social inequalities in the prevalence of CKD and point to the need to prevent this important health problem, as Brazilians are ageing fast and the rapid increase in obesity prevalence in the country threatens the prevention and control of diabetes and hypertension, the most common CKD risk factors.

\section{What is already known on this subject}

- Chronic kidney disease (CKD) is a major worldwide public health problem, but data on CKD in developing countries are scarce.

- The numbers of patients on maintenance dialysis or kidney transplants in Latin America have increased in recent years.

- However, data on early stages of CKD are not available for Latin American countries.

\section{What this study adds}

- On the basis of the $2012 \mathrm{KDIGO}^{6}$ criteria for low glomerular filtration rate and high urine albumin excretion, about 1 in every 10 adults from three regions of Brazil enrolled in the Brazilian Longitudinal Study of Adult Health (ELSA)-Brasil cohort has CKD.

- The prevalence of CKD is higher among low educated, black, 'pardo' and indigenous individuals.

- The most common clinical and laboratorial risk factors for CKD did not explain social inequality in CKD prevalence. 
Contributors $\mathrm{SMB}, \mathrm{RML}$ and JGM were involved in the research idea and study design; SMB, MIS, BBD, PAL, JGM, RHG, IMB, DC, RML and APR were involved in the data acquisition; SMB, JGM, MIS, BBD, PAL, AAL, PGV, IMB, RHG, DC, RML and APR were involved in the data analysis/interpretation; SMB and RML were involved in the statistical analysis. Each author contributed important intellectual content during manuscript drafting or revision and accepts accountability for the overall work by ensuring that questions pertaining to the accuracy or integrity of any portion of the work are appropriately investigated and resolved. SMB takes responsibility that this study has been reported honestly, accurately and transparently.

Funding The study is supported by the Brazilian Ministry of Health (Department of Science and Technology) and Ministry of Science, Technology and Innovation (FINEP Financiadora de Estudos e Projetos), grants no. 0106 0010.00, 0106 0212.00, 01 06 0300.00, 0106 0278.00, 01060115.00 and 01060071.00 and CNPq (the National Council for Scientific and Technological Development).

Competing interests None declared.

Ethics approval National Ethics Commity of the Brazilian Ministry of Health.

Provenance and peer review Not commissioned; externally peer reviewed.

Data sharing statement The data used in this study are available for research proposal on request to the ELSA's Datacenter and to the ELSA's Publications Committee (publiELSA). Additional information can be obtained from the ELSA's Datacenter (estatisticaelsa@ufrgs.br) and from the ELSA Coordinator from the Research Center of Minas Gerais (sbarreto@medicina.ufmg.br).

\section{REFERENCES}

1 Schoolwerth AC, Engelgau MM, Hostetter TH, et al. Chronic kidney disease: a public health problem that needs a public health action plan. Prev Chronic Dis 2006;3:A57. http://www.cdc.gov/pcd/issues/2006/apr/05_0105.htm

2 Chin HJ, Ahn JM, Na KY, et al. The effect of the World Kidney Day campaign on the awareness of chronic kidney disease and the status of risk factors for cardiovascular disease and renal progression. Nephrol Dial Transplant 2010;25:413-19.

3 Matsushita K, van der Velde M, Astor BC, et al. Association of estimated glomerular filtration rate and albuminuria with all-cause and cardiovascular mortality in general population cohorts: a collaborative meta-analysis. Lancet 2010;375:2073-81

4 van der Velde M, Matsushita K, Coresh J, et al. Lower estimated glomerular filtration rate and higher albuminuria are associated with all-cause and cardiovascular mortality. A collaborative meta-analysis of high-risk population cohorts. Kidney Int 2011;79:1341-52.

5 Astor BC, Matsushita K, Gansevoort RT, et al. Lower estimated glomerular filtration rate and higher albuminuria are associated with mortality and end-stage renal disease. A collaborative meta-analysis of kidney disease population cohorts. Kidney Int 2011:79:1331-40.

6 Kidney Disease: Improving Global Outcomes (KDIGO) CKD Work Group. KDIGO 2012 Clinical Practice Guideline for the Evaluation and Management of Chronic Kidney Disease. Kidney Inter Supp/ 2013;3:1-150.

7 Wen CP, Cheng TY, Tsai MK, et al. All-cause mortality attributable to chronic kidney disease: a prospective cohort study based on 462293 adults in Taiwan. Lancet 2008:371:2173-82

8 Chadban SJ, Briganti EM, Kerr PG, et al. Prevalence of kidney damage in Australian adults: the AusDiab kidney study. J Am Soc Nephrol 2003:14(7 Suppl 2):S131-8.

9 Coresh J, Selvin E, Stevens LA, et al. Prevalence of chronic kidney disease in the United States. JAMA 2007;298:2038-47.

10 Coresh J, Astor BC, Greene T, et al. Prevalence of chronic kidney disease and decreased kidney function in the adult US population: third National Health and Nutrition Examination Survey. Am J Kidney Dis 2003:41:1-12.

11 Cusumano AM, González-Bedat MC. Chronic kidney disease in Latin America: time to improve screening and detection. Clin J Am Soc Nephrol 2008:3:594-600.

12 Lugon JR, Strogoff de Matos JP. Disparities in end-stage renal disease care in South America. Kidney Int Suppl (2011). 2013;3(2):153-156. Clin Nephrol 2010;74(Suppl 1):S66-71.

13 Cusumano AM, Gonzalez-Bedat MC, García-García G, et al. Latin American dialysis and renal transplant registry: 2008 report (data 2006). Clin Nephrol 2010;74(Supp 1):S3-8.

14 Correa-Rotter R, Cusumano AM. Present, prevention, and management of chronic kidney disease in Latin America. Blood Purif 2008;26:90-4.

15 Anand S, Bitton A, Gaziano T. The gap between estimated incidence of end-stage renal disease and use of therapy. PLOS ONE 2013;8:e72860.

16 Cusumano AM, Garcia-Garcia G, Gonzalez-Bedat MC, et al. Latin American Dialysis and Transplant Registry: 2008 prevalence and incidence of end-stage renal disease and correlation with socioeconomic indexes. Kidney Int Suppl 2013:3:153-6.

17 Ministry of Health, Brazil—DATASUS —Vital Statistics. http://www2.datasus.gov.br/ DATASUS/index.php?area=0205 (accessed 13 Oct 2014).
18 de Moura L, Prestes IV, Duncan BB, et al. Dialysis for end stage renal disease financed through the Brazilian National Health System, 2000 to 2012. BMC Nephrol 2014;15:111.

19 Sesso RC, Lopes AA, Thomé FS, et al. Report of the Brazilian chronic dialysis census 2012. J Bras Nefrol 2014;36:48-53.

20 Delanaye $\mathrm{P}$; Mariat $\mathrm{C}$; Maillard N, et al. Are the creatinine-based equations accurate to estimate glomerular filtration rate in African American populations? Clin J Am Soc Nephrol 2011:6:906-12.

21 Matsushita K, Mahmoodi BK, Woodward M, et al. Comparison of risk prediction using the CKD-EPI equation and the MDRD study equation for estimated glomerular filtration rate. JAMA 2012;307:1941-5.

22 Levey $\mathrm{AS}$, Stevens $\mathrm{LA}$, Schmid $\mathrm{CH}$, et al. A new equation to estimate glomerular filtration rate. Ann Intern Med 2009;150:604-12.

23 Earley A, Miskulin D, Lamb EJ, et al. Estimating equations for glomerular filtration rate in the era of creatinine standardization: a systematic review. Ann Intern Med 2012;156:785-95.

24 Matsushita K, Selvin E, Bash LD, et al. Risk implications of the new CKD Epidemiology Collaboration (CKD-EPI) equation compared with the MDRD Study equation for estimated GFR: the Atherosclerosis Risk in Communities (ARIC) Study. Am J Kidney Dis 2010;55:648-59.

25 Zanocco JA, Nishida SK, Passos MT, et al. Race adjustment for estimating glomerular filtration rate is not always necessary. Nephron Extra 2012;2: 293-302.

26 Veronese FV, Gomes EC, Chanan J, et al. Performance of CKD-EPI equation to estimate glomerular filtration rate as compared to MDRD equation in South Brazilian individuals in each stage of renal function. Clin Chem Lab Med 2014;52:1747-54.

27 Lora CM, Daviglus ML, Kusek JW, et al. Chronic kidney disease in United States Hispanics: a growing public health problem. Ethn Dis 2009;19:466-72.

28 Crews DC, Charles RF, Evans MK, et al. Poverty, race, and CKD in a racially and socioeconomically diverse urban population. Am J Kidney Dis 2010;55:992-1000.

29 Fraser SD, Roderick P, Aitken GR, et al. Chronic kidney disease, albuminuria and socioeconomic status in the Health Surveys for England 2009 and 2010. J Public Health 2014;36:577-86.

30 Peralta CA, Vittinghoff E, Bansal N, et al. Trajectories of kidney function decline in young black and white adults with preserved GFR: results from the Coronary Artery Risk Development in Young Adults (CARDIA) study. Am J Kidney Dis 2013;62:261-6

31 Shoham DA, Vupputuri S, Diez Roux AV, et al. Kidney disease in life-course socioeconomic context: the Atherosclerosis Risk in Communities (ARIC) Study. Am J Kidney Dis 2007:49:217-26.

32 Evans $\mathrm{K}$, Coresh J, Bash LD, et al. Race differences in access to health care and disparities in incident chronic kidney disease in the US. Nephrol Dial Transplant 2011;26:899-908.

33 Krop JS, Coresh J, Chambless L, et al. A community-based study of explanatory factors for the excess risk for early renal function decline in blacks vs whites with diabetes: the Atherosclerosis Risk in Communities study. Arch Intern Med 1999:159:1777-83.

34 Rasella D, Harhay MO, Pamponet ML, et al. Impact of primary health care on mortality from heart and cerebrovascular diseases in Brazil: a nationwide analysis of longitudinal data. BMJ 2014;349:94014.

35 Silva D Petroski EL, Peres MA. Prehypertension and hypertension among adults in a metropolitan area in Southern Brazil: population-based study. Rev Saude Publica 2012;46:988-98

36 de Miranda VA, Cruz Filho RA, de Oliveira TS, et al. Racial differences in HbA1c: a cross-sectional analysis of a Brazilian public primary care population. Prim Care Diabetes 2013;7:135-41

37 Moreira GC, Cipullo JP, Ciorlia LA, et al. Prevalence of metabolic syndrome: association with risk factors and cardiovascular complications in an urban population. PLOS ONE 2014;9:e105056.

38 Bryson CL, Ross HJ, Boyko EJ, et al. Racial and ethnic variations in albuminuria in the US Third National Health and Nutrition Examination Survey (NHANES III) population: associations with diabetes and level of CKD. Am J Kidney Dis 2006:48:720-6.

39 Ritz E. Hypertension and kidney disease. Clin Nephrol 2010;74(Suppl 1):S39-43.

40 Aquino EM, Barreto SM, Benseñor IM, et al. Brazilian longitudinal study of adult health (ELSA-Brasil): objectives and design. Am J Epidemiol 2012;175: $315-24$.

41 Schmidt MI, Duncan BB, Mill JG, et al. Cohort profile: Iongitudinal Study of Adult Health (ELSA-Brasil). Int J Epidemiol 2015;44:68-75.

42 Bensenor IM, Griep RH, Pinto KA, et al. Routines of organization of clinical tests and interviews in the ELSA-Brasil investigation center. Rev Saúde Publica 2013;47 (Suppl 2):37-47.

43 Fedeli $L G$, Vidigal $P G$, Leite $C M$, et al. Logistics of collection and transportation of biological samples and the organization of the central laboratory in the ELSA-Brasil. Rev Saude Publica 2013;47(Suppl 2):63-71.

44 Said S, Hernandez GT. The link between chronic kidney disease and cardiovascular disease. J Nephropathol 2014;3:99-104. 
45 Li L, Yang C, Zhao Y, et al. Is hyperuricemia an independent risk factor for new-onset chronic kidney disease?: a systematic review and meta-analysis based on observational cohort studies. BMC Nephrol 2014;15:122.

46 Fraser SDS, Aitken G, Taal MW, et al. Exploration of chronic kidney disease prevalence estimates using new measures of kidney function in the health survey for England. PLOS ONE 2015;10:e0118676.

47 Wen CP, Matsushita K, Coresh J, et al. Relative risks of chronic kidney disease for mortality and end-stage renal disease across races are similar. Kidney Int 2014;86:819-27.

48 Al-Qaoud TM, Nitsch D, Wells J, et al. Socioeconomic status and reduced kidney function in the Whitehall II Study: role of obesity and metabolic syndrome. Am J Kidney Dis 2011;58:389-97..

49 Sarnak MJ, Levey AS, Schoolwerth AC, et al. Kidney disease as a risk factor for development of cardiovascular disease: a statement from the American Heart Association Councils on Kidney in Cardiovascular Disease, High Blood Pressure Research, Clinical Cardiology, and Epidemiology and Prevention. Circulation 2003;108:2154-69.

50 Appel LJ, Wright JT Jr, Greene T, et al. Intensive blood-pressure control in hypertensive chronic kidney disease. N Engl J Med 2010;

363:918-29.

51 Fassett RG, Venuthurupalli SK, Gobe GC, et al. Biomarkers in chronic kidney disease: a review. Kidney Int 2011;80:806-21.

52 Hallan SI, Ritz E, Lydersen $\mathrm{S}$, et al. Combining GFR and albuminuria to classify CKD improves prediction of ESRD. J Am Soc Nephrol 2009;20:1069-77.

53 Go AS, Chertow GM, Fan D, et al. Chronic kidney disease and the risks of death, cardiovascular events, and hospitalization. $N$ Engl J Med 2004;351:1296-305.

54 Patzer RE, McClellan WM. Influence of race, ethnicity and socioeconomic status on kidney disease. Nat Rev Nephrol 2012;8:533-41.

55 Chor D, Ribeiro AL, Carvalho MS, et al. Prevalence, awareness, treatment and influence of socioeconomic variables on control of high blood pressure: results of the ELSA-Brasil Study. PLOS ONE 2015;9:e108426.

56 Lotufo PA, Pereira AC, Vasconcellos PS, et al. Resistant hypertension: risk factors, subclinical atherosclerosis, and comorbidities among adults- the Brazilian
Longitudinal Study of Adult Health (ELSA-Brasil). J Clin Hypertens (Greenwich) 2015;17:74-80.

57 Schmidt Ml, Hoffmann JF, de Fátima Sander Diniz M, et al. High prevalence of diabetes and intermediate hyperglycemia - The Brazilian Longitudinal Study of Adult Health (ELSA-Brasil). Diabetol Metab Syndr 2014;6:123.

58 Stevens LA, Claybon MA, Schmid CH, et al. Evaluation of the Chronic Kidney Disease Epidemiology Collaboration equation for estimating the glomerular filtration rate in multiple ethnicities. Kidney Int 2011;79:555-62.

59 Gonçalves VF, Carvalho CM, Bortolini MC, et al. The phylogeography of African Brazilians. Hum Hered 2008;65:23-32.

60 Stefflova K, Dulik MC, Barnholtz-Sloan JS, et al. Dissecting the within-Africa ancestry of populations of African descent in the Americas. PLOS ONE 2011;6: e14495.

61 Rule AD, Teo BW. GFR Estimation in Japan and China: What Accounts for the Difference?. Am J Kidney Dis 2009;53:932-5.

62 Ho E, Teo BW. Assessing kidney function in Asia. Singapore Med J 2010;51:888-93.

63 Delanaye PE, Cavalier C, Mariat J, et al. Estimating glomerular filtration rate in Asian subjects: where do we stand? Kidney Int 2011;80:439-40.

64 Barreto SM, Ladeira RM, Bastos MS, et al. ELSA Brasil strategies for outcome identification, investigation and ascertainment. Rev Saude Publica 2013;47(Suppl 2):79-86.

65 Fedewa SA, McClellan WM, Judd S, et al. The association between race and income on risk of mortality in patients with moderate chronic kidney disease. BMC Nephrol 2014;15:136.

66 Pollitt RA, Rose KM, Kaufman JS. Evaluating the evidence for models of life course socioeconomic factors and cardiovascular outcomes: a systematic review. BMC Public Health 2005;5:7.

67 Vart $\mathrm{P}$, Scheven L, Lambers Heerspink HJ, et al. Urine albumin-creatinine ratio versus albumin excretion for albuminuria staging: a prospective longitudinal cohort study. Am J Kidney Dis 2015. Epub ahead of print doi:10.1053/j.ajkd. 2015.05.025

68 Lusignan S, Tomson C, Harris K, et al. Creatinine fluctuation has a greater effect than the formula to estimate glomerular filtration rate on the prevalence of chronic kidney disease. Nephron Clin Pract 2011;117:c213-24. 